\title{
Effectiveness of fluid viscous damper for steel frame building subjected to earthquake load
}

\author{
Thanh Binh Pham* and Ngoc Quang Vu \\ Institute of Techniques for Special Engineering, Le Quy Don Technical University, Viet Nam
}

\begin{abstract}
Since the appearance of the first modern multistories buildings, besides the demand of ensuring the bearing capacity, one of the urgent problems facing the engineer is to do how to design structure to ensure the requirements of normal use such as displacement, motion acceleration within permissible limits. There exist many methods to reduce these response of structure under lateral load. Among these, using fluid viscous damper (FVD) is one of the most applied equipment because of its simplicity. This paper presents the examination of eight-story steel frame structure subjected to seismic load. The FVD system is defined in Etabs with link properties. In each story, four dampers are located in each direction of plan, with two on each side of the center of stiffness of the story. The time history analysis was conducted to study the structure subjected to seimic load collected from the function library of program Etabs. The effect of FVD system was determined by the dynamic response of the building and displacement indexes such as maximum displacement of roof, story drift ratio. The results show that, all the dynamic response characters of structure were decreased significantly when providing the FVD to it.
\end{abstract}

\section{Introduction}

In the modern life, with the strength of economy, science, technology, especially civil engineering science, there is pressing problem arises in large urban areas. It is a high labor density. This requires the construction of multistories, high-rise buildings with severe flexibility [3], with increasement of response in result. Among these loads, earthquake is unpredictable and very dangerous to human. There were many earthquake catastrophe that caused the death of many people and destruction, severe damage of many buildings. The important and practical subject for structural design engineering is finding the way to minimize losses. The traditional method is modification of stiffness. But this is not always the most effective mean.

One of the more practical and effective method is using the damping equipment in the structure to increase the damping ratio up to 30 percentage [11]. This is approach so-called "energy dissipation".

The relationship of energy is presented by this formula:

\footnotetext{
${ }^{*}$ Corresponding author: ptb@lqdtu.edu.vn
} 
Where:

$$
E(t)=E_{k}(t)+E_{s}(t)+E_{h}(t)+E_{d}(t)
$$

$E(t)$ - earthquake energy;

$E_{k}(t)$ - kinetic energy;

$E_{s}(t)$ - elastic strain energy;

$E_{h}(t)$ - energy dissipated by the structure through viscous and hysteretic;

$E_{d}(t)$ - energy dissipated by the damper.

In earthquake engineering, the common way is introduction of devices with damping characters for changing the $E_{d}$. Therefore, the large seismic energy can be absorbed by these devices. In the monograph [2], Alberto Lago et al listed all the applications, which are being developed to solve the energy absorption problem. They are active, passive, semiactive and hybrid control. Among the passive systems [2] (see Fig. 1), the fluid viscous dampers (FVD) - passive control system are one of the most applied equipment because of its simplicity.

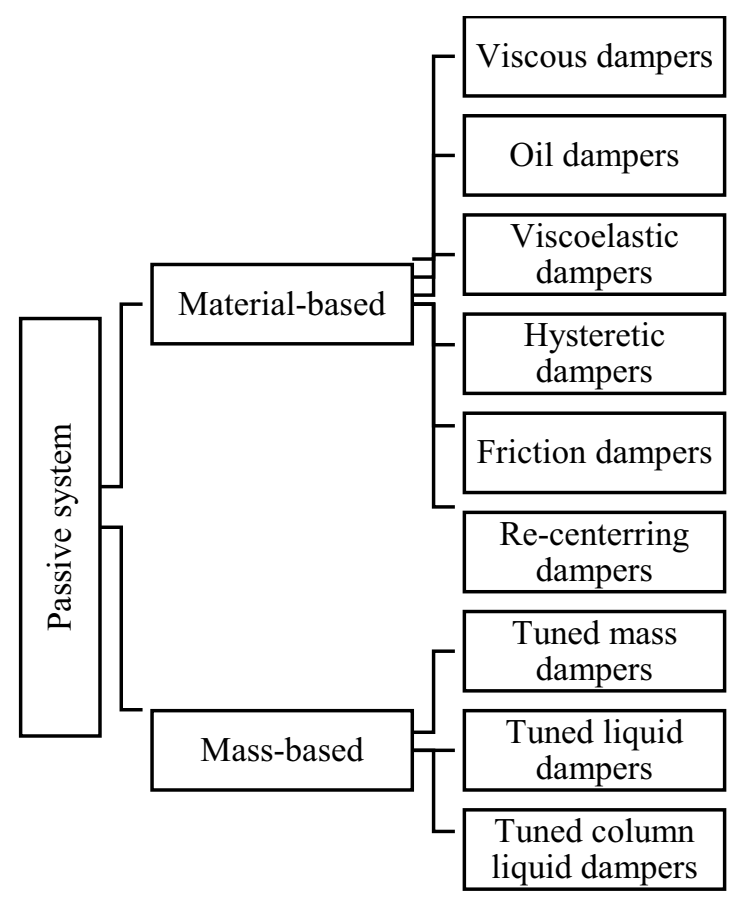

Fig. 1. Possible passive damping systems for tall buildings [2]

The dynamic response of structure with the supplied FVD system is analyzed with following objects:

- Determination of the effect of FVD on the fundamental modes of structure;

- Examination of structure response under seismic load through indexes: base shear, displacement and story drift.

\section{Basic of Fluid viscous damper}

Fluid viscous dampers were first applied in the aerospace industry for military purposes. In structural engineering, they were introduced in the late 1980s [11]. It can be incorporated into both new buildings and existing buildings $[1,2,4,5,7,9,12,13,14,15]$. They are 
placed between any two joints where relative motion exists during transient event such as earthquake or wind. The principle of the FVD works is to provide resistance force through movement. They almost don't modify any stiffness of structure, and do not carry any static loads [16]. A FVD device is velocity dependent device (see formula 2). It consists of a piston, which moves back and forth in the viscous fluid to generate high pressure [16].

FVD performance is characterized by this relationship:

$$
F=C V^{\alpha}
$$

Where:
$F$ - damping force;
$V$ - relative velocity;
$C$ - damping coefficient;
$\alpha$ - velocity exponent.

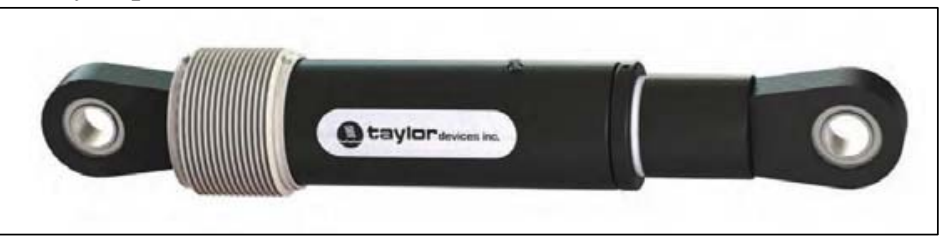

Fig. 2. Taylor seismic dampers for building applications [16]

As the velocity exponent decreases the damping efficiency increases. Values from 0.3 to 0.9 are best for building applications $[1,2,16]$. From the beginning of the design, the standard $\alpha$ is chosen 0.5 . As stated in [11], the nonlinear damper with $\alpha<1$ provides better damping force than others with $\alpha=1$ - linear and $\alpha>1$, which are rarely used.

The FVD in the structure can be modeled in structural program Etabs by introducing a linear link with type as damper and exponential. The FVD is connected from joint to joint in diagonal direction within the height of story. It has been proved to be the most effective form of FVD.

\section{Numerical examples and discussion}

To understand the effectives of FVD system (Fig. 3), authors examined the eight-story steel frame structure subjected to seismic load. The time history analysis was conducted.

The structure was modeled with following data: all columns with frame section W14x68, all beams with section W14x26; elastic module is $E=2.0 \mathrm{e}+8(M P a)$; modal damping of structure is $\xi=0.05$. The seismic action recorded at the Newhall station was taken from the time history functions library of Etabs and was applied to the structure in the OY direction.

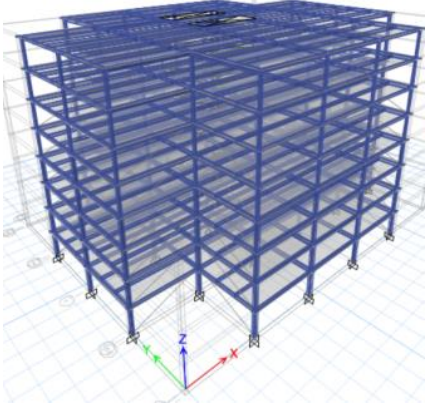

a)

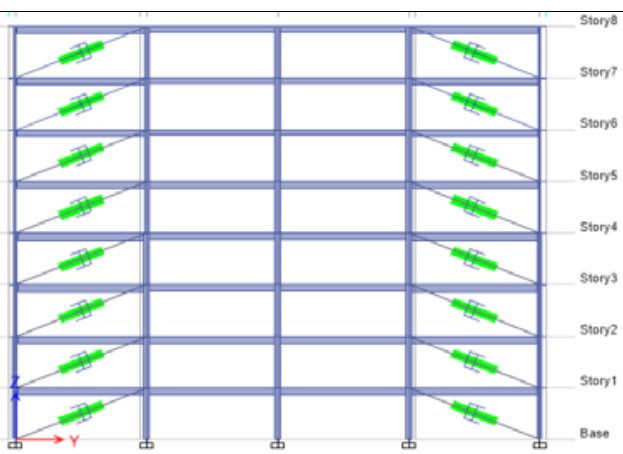

b)

Fig. 3. The analyzed steel frame structure. 


\subsection{Effectiveness of FVD on modal modes of structure}

FVD are provided in each story in two direction. In each story, four dampers are located in each direction, with two on each side of the center of stiffness of the story in the considering direction. The FVD are considered to be nonlinear, so that the $\alpha=0.4$.

First translating modes in the $\mathrm{OX}$ and $\mathrm{OY}$ directions of the initial structure and structure attached FVD are demonstrated in Fig. 4 and Fig. 5. The periods of modes in both cases are presented in Table 1. From the results, it can be judged that with the FVD, the modal modes almost stayed the same. It can be explained that the FVD system does not affect to the stiffness of the structure.

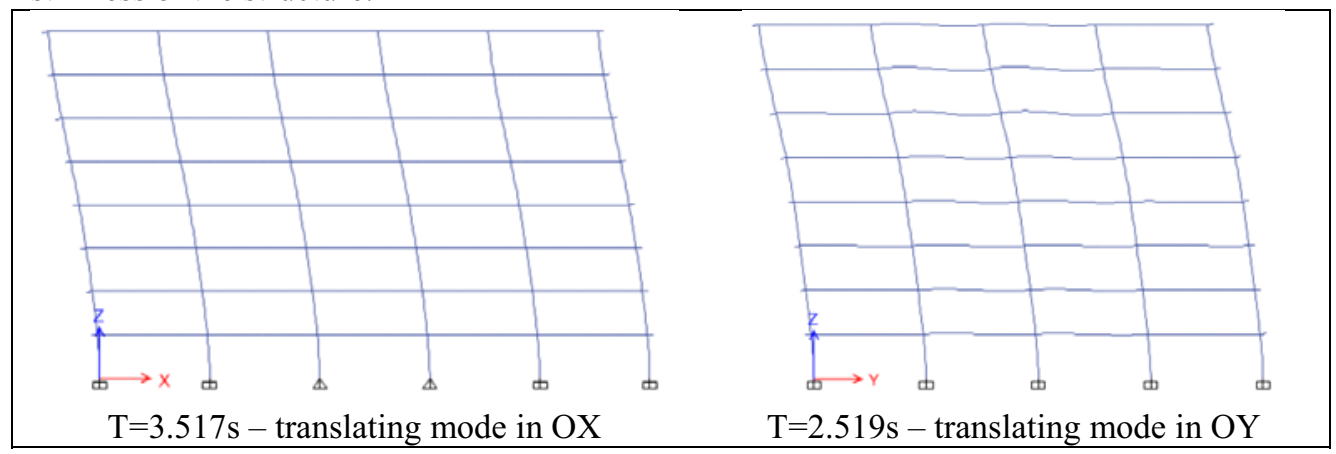

Fig. 4. Modal shapes of initial structure.

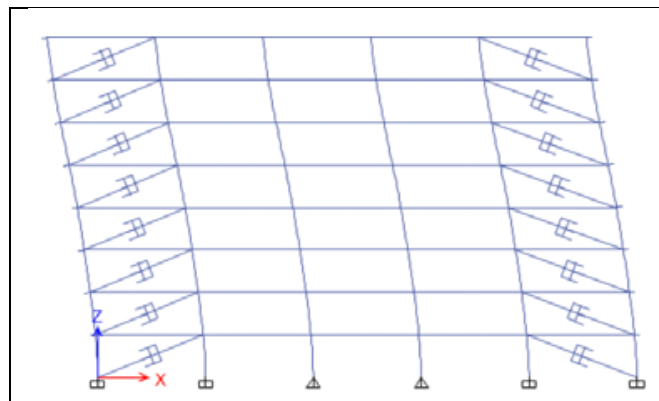

$\mathrm{T}=3.517 \mathrm{~s}-$ translating mode in $\mathrm{OX}$

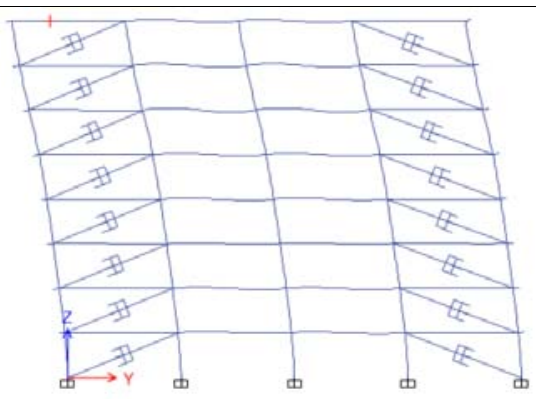

$\mathrm{T}=2.517 \mathrm{~s}-$ translating mode in $\mathrm{OY}$

Fig. 5. Modal shapes of structure with FVD.

Table 1. Periods of building modes in both cases.

\begin{tabular}{|c|c|c|c|c|c|c|c|c|c|}
\hline \multirow{4}{*}{ Mode } & \multicolumn{2}{|c|}{ Periods - Translation OX } & \multicolumn{2}{c|}{ Periods - Translation OY } & \multicolumn{3}{c|}{ Periods - Rotation OZ } \\
\cline { 2 - 10 } & $\begin{array}{c}\text { Without } \\
\text { FVD } \\
\text { (s) }\end{array}$ & $\begin{array}{c}\text { With } \\
\text { FVD } \\
\text { (s) }\end{array}$ & $\begin{array}{c}\text { Diff. } \\
\text { ratio } \\
\text { (\%) }\end{array}$ & $\begin{array}{c}\text { Without } \\
\text { FVD } \\
\text { (s) }\end{array}$ & $\begin{array}{c}\text { With } \\
\text { FVD } \\
\text { (s) }\end{array}$ & $\begin{array}{c}\text { Diff. } \\
\text { ratio }\end{array}$ & $\begin{array}{c}\text { Without } \\
\text { FVD } \\
\text { (s) }\end{array}$ & $\begin{array}{c}\text { With } \\
\text { FVD } \\
\text { (s) }\end{array}$ & $\begin{array}{c}\text { Diff. } \\
\text { ratio }\end{array}$ \\
\hline$(1)$ & $(2)$ & $(3)$ & $(4)$ & $(5)$ & $(6)$ & $(7)$ & $(8)$ & $(9)$ & $(10)$ \\
\hline 1 & 3.517 & 3.517 & 0.00 & 2.519 & 2.517 & 0.08 & 1.907 & 1.872 & 1.87 \\
\hline 2 & 1.472 & 1.467 & 0.34 & 1.152 & 1.126 & 2.31 & 0.858 & 0.848 & 1.18 \\
\hline 3 & 0.728 & 0.726 & 0.28 & 0.551 & 0.542 & 1.66 & 0.425 & 0.422 & 0.71 \\
\hline 4 & 0.441 & 0.441 & 0.00 & 0.347 & 0.345 & 0.58 & 0.270 & 0.270 & 0.00 \\
\hline
\end{tabular}

\subsection{Base shear and displacement}

The effectiveness of FVD system was also evaluated by reviewing the base shear and displacement plots of the node 1 on top of the structure without FVD (WOFVD) and with 
FVD (WFVD) in both directions OX and OY, which are presented in Fig.6 - Fig.9, respectively. From the results, it can be noted that, using FVD decreased the base FX by $14 \%$ from $6342 \mathrm{kN}$ to $5456 \mathrm{kN}$ (Fig.6), the base FY by $23.3 \%$ from $9818 \mathrm{kN}$ to $7532 \mathrm{kN}$ (Fig.7). The maximum top-story node displacement UX was decreased by $76.5 \%$ from $939 \mathrm{~mm}$ to $211 \mathrm{~mm}$ (Fig.8), displacement UY - by $65 \%$ from $603 \mathrm{~mm}$ to $210 \mathrm{~mm}$ (Fig.9) .

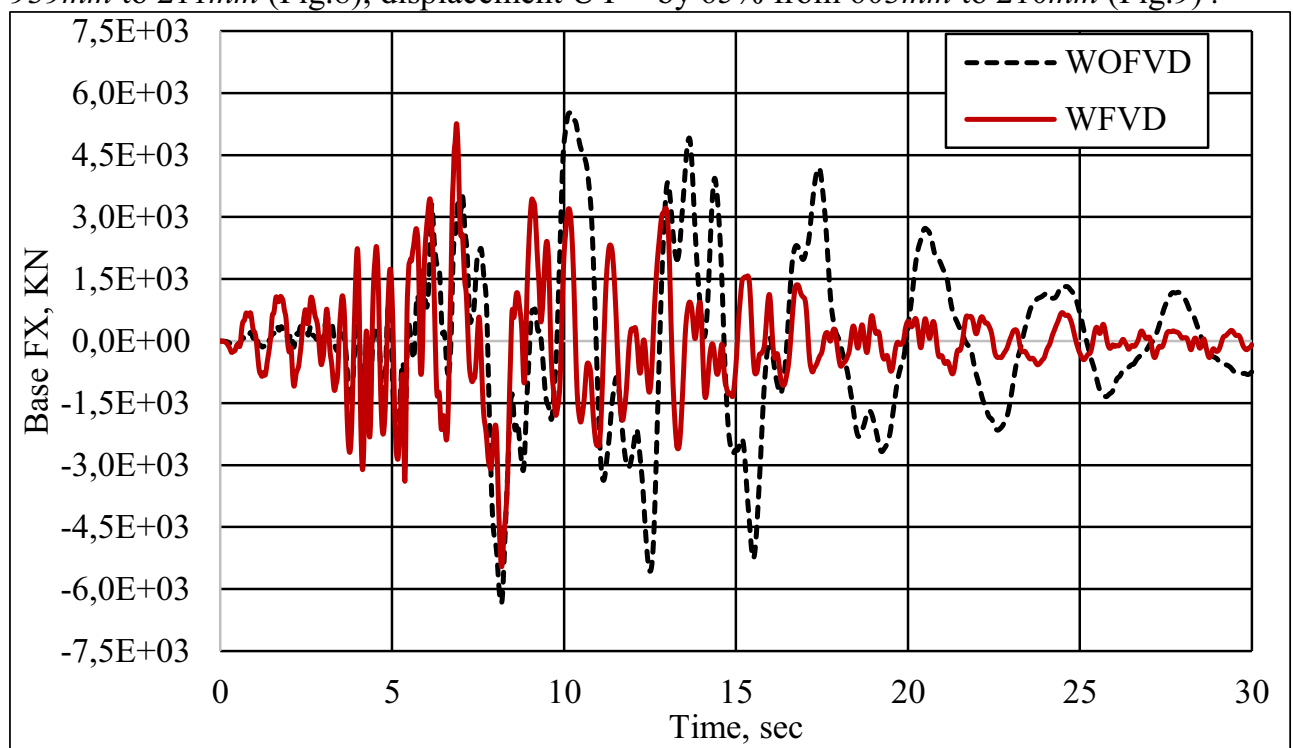

Fig. 6. Base FX of model.

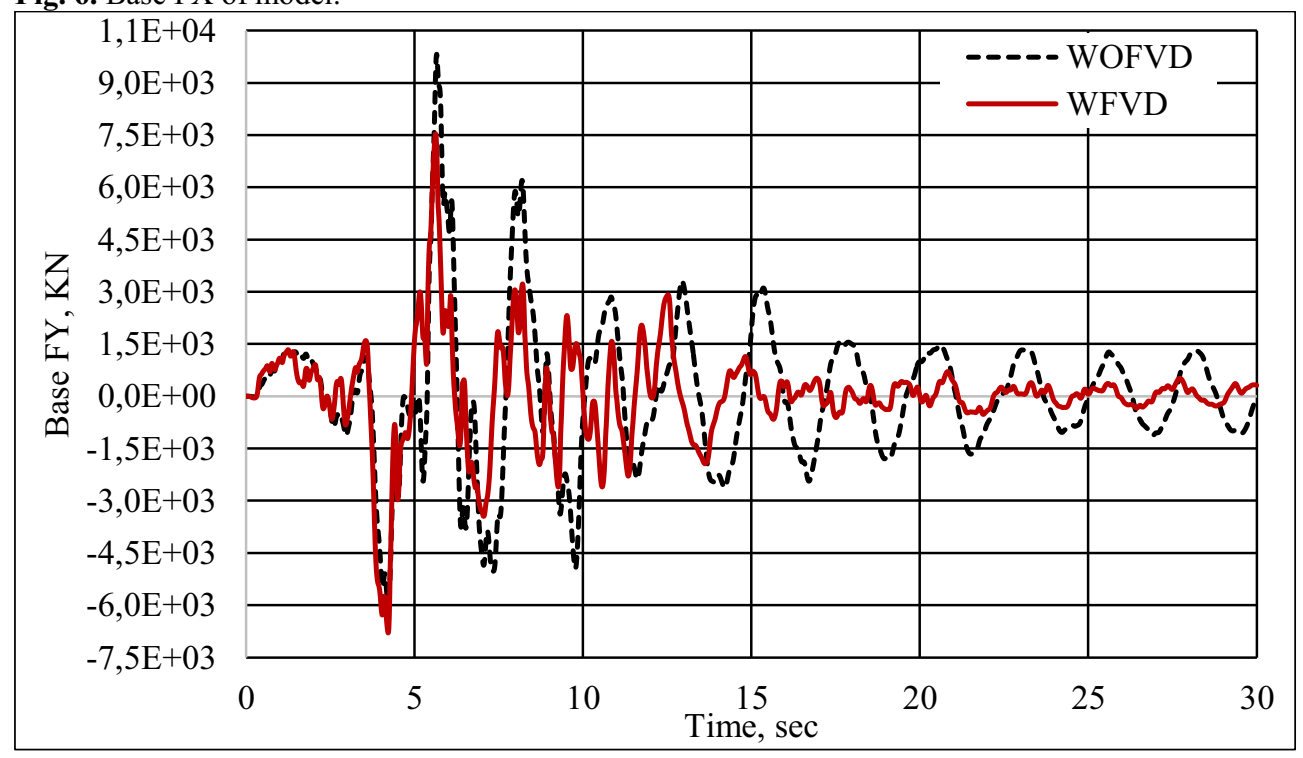

Fig. 7. Base FY of model. 


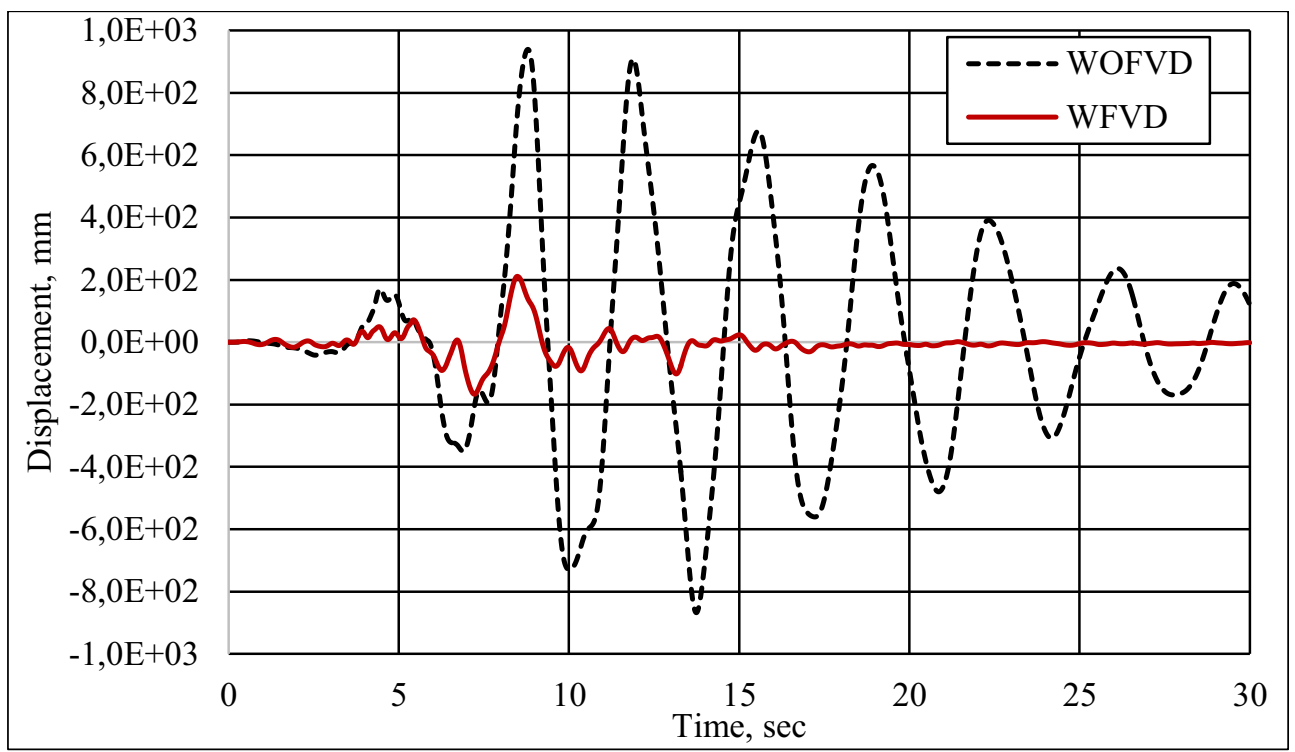

Fig. 8. Top node displacement of structure in OX direction.

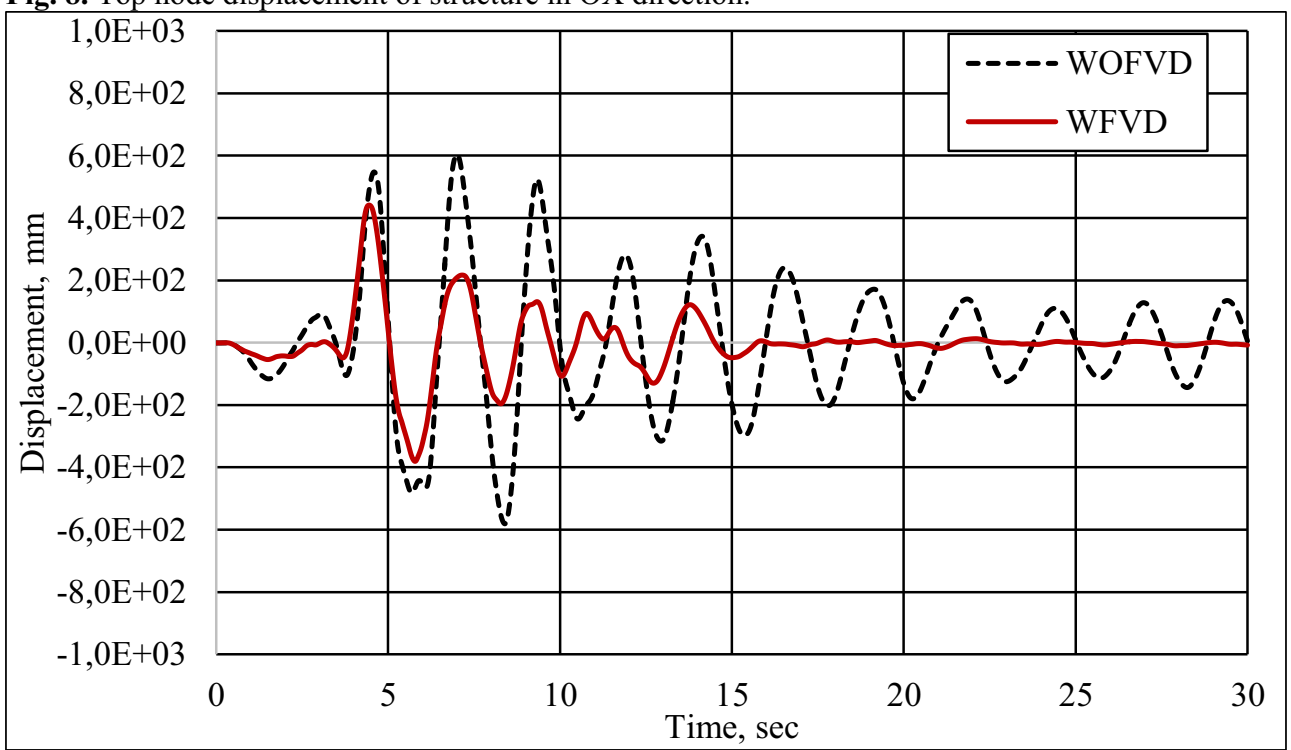

Fig. 9. Top node displacement of structure in OY direction.

\subsection{Maximum story drift}

One of the important indexes to judge about the response of structure under earthquake is inter-story drift. It must be within some range to ensure not make damages to the devices, equipment of the building. The maximum story drift was plotted in Fig. 10 to understand the effect of FVD system. The Fig.10, a indicated the maximum story drifts in the OX direction, and the Fig.10,b - in the OY direction. The results showed that, the maximum story drifts changed more evenly along the height of structure when using FVD. 


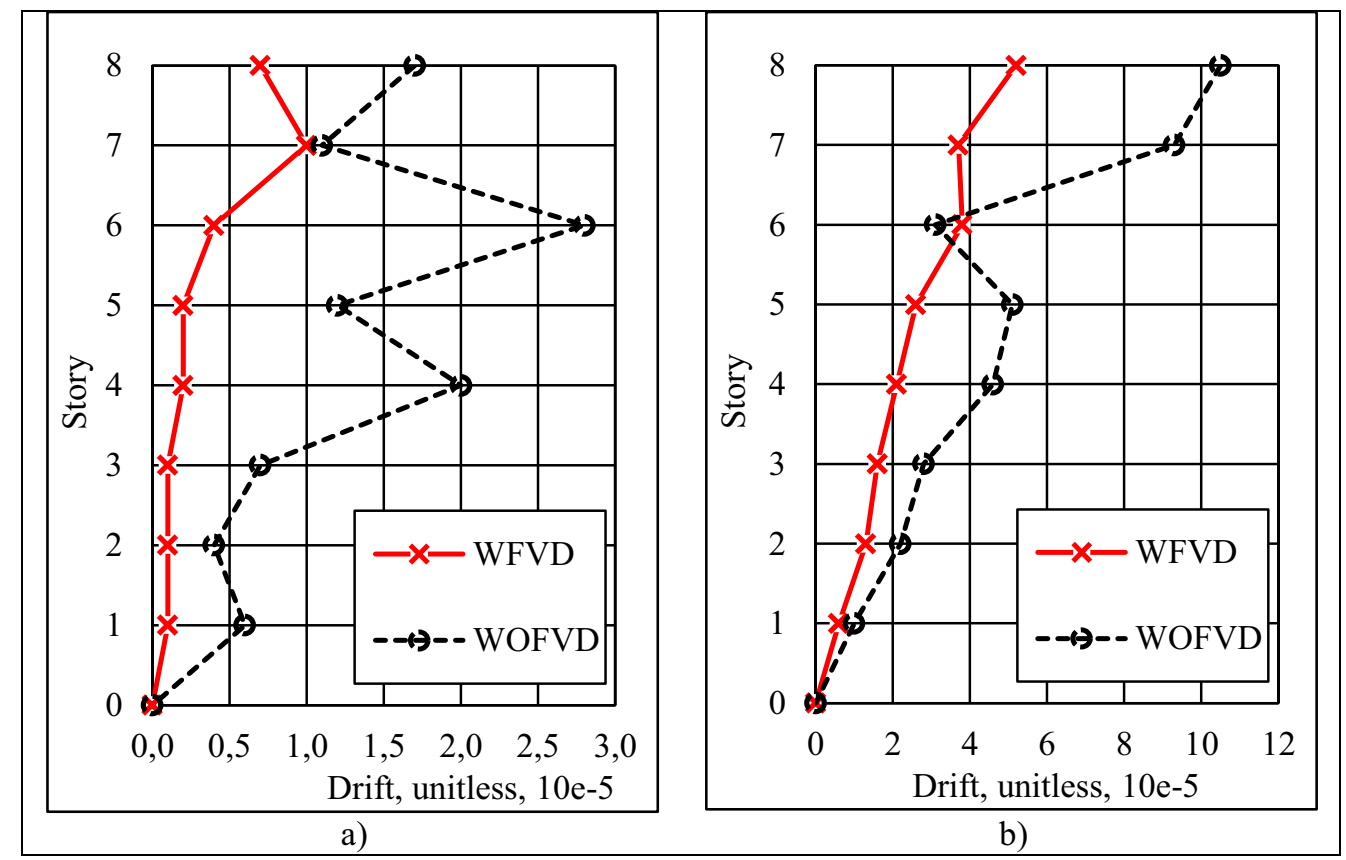

Fig. 10. Maximum story drift of structure: a) in X-direction; b) in Y-direction

\section{Conclusions}

From the results of dynamic study of eight-story steel frame structure subjected to earthquake load, the effectiveness of fluid viscous dampers was evaluated. The base shear and displacement of top-story are significantly decreased. The maximum story drift was also reduced with the provided fluid viscous damper. The changes in top displacement and story drift are significant, meanwhile in base shear are less.

\section{References}

1. A. Li, Vibration Control for Building Structures: Theory and Applications (Springer, 2020)

2. A. Lago, D. Trabucco, A. Wood, Damping Technologies for Tall Buildings: Theory, Design Guidance and Case (CTBUH \& Elsevier, 2018)

3. B.S. Taranath, Tall Building Design: Steel, Concrete, and Composite Systems (CRC Press, 2016)

4. J.J. Connor, Introduction to Structural Motion Control (Prentice Hal, 2002)

5. M.C. Constatinou, M.D. Syman, Experimental and analytical investigation of seismic response of structures with supplemental fluid viscous dampers Buffalo, NY: National Center for earthquake engineering research, (1992)

6. J.P. Den Hartog, 1956 Mechanical Vibration (McGraw-Hill, New York, 1956)

7. D. Lee, D.P Taylor, Struct. Des. Tall Build. 10(5) 311-20 (2001)

8. Mcnamara, J. Robert, P. Douglas, Taylor, Struct. Des. Tall Build. 12.2 145-154 (2003).

9. H.K. Miyamoto, A.S. Gilani, A. Wada, State of the art design of steel moment frame buildings with dampers, in Proceedings of the 14th World Conference on Earthquake Engineering, 12-17 October 2008, Beijing, China

10. N. Pollini, O. Lavan, O. Amir, Earthqu. Eng. Struct. Dyn. 46 1941-1961 (2017) 
11. A. Ras, N. Boumechra, Alex. Eng. J. 55 2821-2832 (2016)

12. A.A. Seleemah, C.C. Michalakis, Investigation of seismic response of buildings with linear and nonlinear fluid viscous dampers Buffalo: National Center for Earthquake Engineering Research (1997)

13. T.T. Soong, G.F. Dargush, Passive Energy Dissipation Systems in Structural Engineering (John Wiley \& Sons, 1997)

14. M.D. Syman, M.C Constatinou, ISET J. Earthq. Technol. 35(4) 185-206 (1998)

15. Taylor Devices Inc. web page. www.taylordevices.com September (2016)

16. Taylor DP, History, Design, and Applications of Fluid Dampers in Structural Engineering Passive Structural Control Symposium, Tokyo Institute of Technology, Tokyo, Japan (2002)

17. P.C. Wang, F. Kozin, F. Amini, Engineering Structures 5(4) 282-288 (1983) 